\title{
Government efforts and roadmaps for building information modeling implementation: lessons from Singapore, the UK, and the US
}

3 Purpose: The government plays a critical role in driving building information modeling (BIM) 4 implementation. This study aims to investigate the government efforts for driving BIM 5 implementation in three benchmark countries: Singapore, the UK, and the US, so as to develop 6 appropriate roadmaps for increasing BIM implementations in other countries.

7 Approach: This study performs a review on the government efforts and roles in BIM 8 implementation in three benchmark countries, namely, Singapore, the UK, and the US.

9 Findings: Through cross comparison with existing literature, it is found that Singapore and the 10 UK adopt a government-driven approach, and a phase-by-phase development pattern is 11 observed. The first phase focuses on the building sector to rapidly increase the use of BIM and 12 the government generally plays the role of an initiator. In the second phase, BIM is expanded 13 to other implementation areas, e.g., smart city. The importance of the initiator role decreases 14 and more attention is paid to supporting roles such as researcher, educator, and regulator. In 15 contrast, an industry-driven approach is adopted in the US. The main role of the government is 16 that of a regulator, with research institutions actively supporting the BIM implementation.

17 Originality/value: General roadmaps of the two mandating approaches are presented. The 18 results can provide a useful reference for countries and regions that intend to develop roadmaps 19 to increase their BIM maturity level and enhance readiness to accept and implement BIM.

20 Keywords: Building information modeling (BIM); Roadmap; Government; BIM mandates.

21 Article Classification: General review.

\section{Introduction}

Building information modeling (BIM) is a set of technologies and solutions that enables threedimensional (3D) representation of geometric and non-geometric (functional) attributes of building elements. Its objective is to improve the collaboration of different stakeholders in the architecture, engineering, and construction (AEC) industry and enhance the productivity and management throughout the building's whole lifecycle (Ghaffarianhoseini et al., 2017). The concept of BIM can date back to the 1960s when computing was in the early stage (Smith, 2014a). With the development of computing, 3D modeling emerged in the early 1970s (Eastman et al., 2011). In 1982, the ArchiCAD software, which is considered by many as the real beginning of BIM, was developed. However, according to Smith (2014a), the true concept of BIM was introduced in the early 2000s when the Revit software was developed (Smith, 2014a). Since then, it has attracted growing research interest and practice. Various BIM tools that can provide sophisticated functions such as 3D parametric modeling, clash detection, fourdimensional (4D) schedule management, five-dimensional (5D) cost modeling, sixdimensional facility management, and performance simulation and visualization are currently available (e.g., energy performance).

38 The benefits of BIM have been thoroughly investigated and documented in previous studies. According to Ghaffarianhoseini et al. (2017), BIM has nine clear benefits including technical, knowledge management, standardization, diversity, integration, economic, planning/scheduling, building lifecycle, and decision support benefits. To explore the extent to which the documented benefits of BIM have been achieved, Bryde et al. (2013) analyzed data 
from 35 construction projects that used BIM. The results show that cost reduction, lifecycle project control, and significant time savings are the most frequently reported benefits. As the largest client of BIM implementation, the government is believed to benefit the most from BIM adoption (Yang and Chou, 2018). As stated by BuildingSMART Australasia (2012), accelerating the use of BIM in Australia will increase the productivity of the built environment sector by $6 \%$ to $9 \%$. It is also reported to save $9.8 \%$ of project costs, reduce $69.1 \%$ of project duration, and reduce $50 \%$ of the efforts required for information exchange (Ghaffarianhoseini et al., 2017). Therefore, the BIM technology has been adopted by many countries to advance the AEC sector (Yang and Chou, 2018, Chan et al., 2019).

10 Despite these distinct benefits, the practical implementation of BIM can be difficult. Although most countries are showing a high level of BIM awareness, the level of implementation is often much lower (Ghaffarianhoseini et al., 2017). According to National Building Specification (NBS, 2016), a typical example is the UK, where $95 \%$ are aware of BIM but only $48 \%$ are using it in 2016. A similar level of disparity between the awareness and implementation of BIM is also observed in Japan, where $92 \%$ are aware but only half have experience with BIM. This is also true for Canada, Denmark, and Czech Republic (NBS, 2016). As such, many studies are initiated to investigate the barriers that impede the BIM implementation. According to Alreshidi et al. (2017), the barriers toward BIM adoption include social-organizational barriers (e.g., lack of motivation, adoption of conventional practices and standards), financial barriers (e.g., BIM adoption cost), technical barriers (e.g., interoperability issues), contractual barriers (e.g., lack of a mature BIM contract) and legal barriers (e.g., BIM model ownership). The cost barriers, interoperability issues, BIM model ownership, intellectual property rights concerns and issues related to the willingness to share data confirm the findings of Bryde et al. (2013). To overcome these barriers, Alreshidi et al. (2017) pointed out that existing standards such as Publicly Available Specifications (PAS) 1192-2 and 3 (BSI, 2013, BSI, 2014a), Industry Foundation Classes (IFC) (BuildingSMART, 1996, International Alliance for Interoperability, 1999), and Construction Operations Building Information Exchange (COBie) (US Army Corps of Engineers, 2007) do have positive effects on the BIM application. However, these standards only provide advices that people generally do not implement unless otherwise required. In addition, Zhou et al. (2019) further revealed six unaddressed barriers towards the BIM implementation and argued that government should play an active role in promoting the BIM use. Lindblad and Guerrero (2020) also recognized clients as a key actor and public policy as a common target in promoting innovation in the AEC sector. As such, government intervention is seen as a necessary strategy for promoting a wider and more efficient BIM implementation, especially for countries that have relatively lagged behind in BIM adoption (Liu et al., 2015, Yang and Chou, 2018, Zhou et al., 2019). Thus, there is a need to find out what the government can do to advance the implementation of BIM technologies.

Existing studies have conducted extensive investigation on the efforts of the government in BIM implementation. For example, Wong et al. (2011) reviewed the BIM initiatives of the US and Hong Kong and discussed the government roles in implementing BIM in different stages of a project's life cycle. Smith (2014a) reviewed the BIM implementation of ten countries and jurisdictions and identified the government leadership as a critical driver. Cheng and $\mathrm{Lu}$ (2015) conducted an extensive review on the efforts of government authorities and non-profit organizations including the goals, implementations, and standards/guidelines of 14 countries/regions and found that they have six roles in BIM adoption. According to the role of the government in the promotion of BIM application, Yang and Chou (2018) demonstrated two typical approaches for promoting BIM in a country, namely, the government-driven approach and industry-driven approach. The government-driven approach is a top-to-bottom approach, 
meaning that the government takes the lead and launches a series of policies (e.g., BIM mandates) to get the industry stakeholders involved. In contrast, the industry-driven approach or the bottom-to-top approach, requires a lower level of government intervention while the industry takes an active part and has a high implementation level. Based on these two approaches, Yang and Chou (2018) proposed a combined approach for Taiwan. These studies offered comprehensive analyses on the strategies and roles of the government in BIM adoption and highlighted the BIM mandate as a good driver for BIM implementation. However, increasing the BIM implementation is a complex and long-term task. Thus, it requires not only knowing what efforts that suit the country's own context should be made and what roles the government can play, but also when to make such efforts and how the roles of the government should change along the BIM adoption journey. Such knowledge is not adequately addressed in existing studies. Therefore, a step-by-step BIM implementation analysis of countries that have a high maturity level is necessary.

Therefore, this study aims to explore the BIM implementation journey of benchmark countries to provide a practical BIM adoption roadmap for countries that are relatively lagging behind. As government efforts are critical to any country (Wong et al., 2011), specific focus is given to the efforts and roles of the government. The rest of this paper is organized as follows: Section 2 provides an overview of the global BIM implementation and mandating status and existing studies on government roles in the diffusion of technological innovation. Section 3 presents the BIM implementation journey in Singapore, the UK, and the US. Section 4 discusses the regular patterns of BIM implementation and the roles of the government along the journey. Section 5 concludes this study.

\section{Literature review}

\subsection{Global BIM adoption rate}

The BIM adoption rate is a widely used indicator to reflect the status of BIM adoption in a certain country or region. It measures the percentage of BIM adoption in the industry. Although it is a rough estimation, it is sufficient to provide an overview of BIM implementation (Yang and Chou, 2018). Table 1 presents the latest figures on general BIM adoption rates for each country/region. As a supplementary to the general BIM adoption rate, the BIM adoption rate in infrastructure and the percentage of high-level BIM use are also provided. The general BIM adoption rates reflect the adoption rate of all stakeholders, and the value of high-level BIM use specifically represents the percentage of BIM users in more than $50 \%$ of their projects. According to Yang and Chou (2018), countries with a general adoption rate of less than $30 \%$, $30 \%$ to $70 \%$, and more than $70 \%$ are regarded to have low, medium, and high BIM adoption levels, respectively. Hence, the BIM adoption level of the countries/regions can be summarized as follows:

- High BIM adoption level: the US, Canada, Denmark, Germany, France, the UK, and Singapore. Because the data on the general BIM adoption rate in Germany and France are extremely outdated to reflect their current levels of adoption, their BIM adoption level is inferred by reference to data on the BIM adoption in infrastructure and the rate of highlevel BIM use.

- Medium BIM adoption level: Japan, China, South Korea, and New Zealand.

- Low BIM adoption level: Czech Republic and Middle East. 


\subsection{Global BIM mandating status}

2 Thus far, many countries worldwide have mandated the use of BIM at different levels. Table 2 3 summarizes the mandating efforts of various countries and indicates that all countries with a 4 high BIM adoption level (BIM adoption rate $>70 \%$ ) except Canada are actively participating 5 in establishing BIM mandates, such as the US, Denmark, Germany, France, and the UK. 6 Among these countries, the US is the first to require mandatory use of BIM in 2007. European 7 countries, such as Denmark, Finland, Norway, the UK, and the Netherlands, are also pioneers 8 in this field. In 2014, a directive was commissioned by the European Parliament to require 9 European Union members to encourage or even mandate BIM in projects that receive public 10 funding (Dodge Data \& Analytics, 2017). This may be one of the most important reasons that 11 BIM mandates become increasingly popular among the European countries since then.

12 Nevertheless, among these European countries, the UK stands out in terms of implementing 13 BIM through government efforts, which is rendered by three facts. First, most European 14 countries intend to implement BIM in particular sectors, i.e., the building or infrastructure 15 sector, and in particular project stages, i.e., planning, design, construction and 16 operation(Waterhouse and Johston, 2018). However, UK features a comprehensive BIM implementation in both building and infrastructure sectors and at all project stages. This can be reflected by the standards published in the UK, which guide BIM usage in projects lifecycle and the different public working groups set for various project types, such as the BIM4 groups that monitor, research and provide assistance to more than 20 sectors, such as highway and public housing (Kemp et al., 2018). Second, despite not being the earliest country that adopts BIM, UK is the only European country that has proposed a clear and long-term BIM roadmap to illustrate the BIM implementation step-by-step to 2020, i.e., the Government Construction Strategy 2011-2016 and 2016-2020 (Cabinet Office, 2011, Cabinet Office, 2016). Third, apart from mandating BIM use, the efforts to promote BIM in most European countries seem to be limited. For instance, Finland and Denmark focused on the technical solutions for BIM, while France and Netherland tried to encourage BIM research and business activities by providing reasonable funding (van Nederveen et al., 2010). Germany and Turkey, on the other hand, demonstrated the benefits of BIM in several major infrastructure projects (Bastian Fuchs, 2017). Finally, in most European countries, the efforts to implement BIM are directly made by government authorities, such as the transportation department and ministry of infrastructure. However, the UK government establishes several specialized organizations, such as the BIM Task Group and the Centre for Digital Built Britain, to ensure centralized and organized government efforts to promote the use of BIM. These specialized organizations are formed by BIM experts from both academia and industry, therefore being more effective in terms of identifying industry problems and proposing specific solutions.

37 In Asia, Singapore shows great ambition in advancing mandatory use of BIM implementation. 38 It pioneered the mandatory use of BIM in the building sector in 2012 and extended the mandate each year until 2015, making Singapore a typical successful country that adopts a governmentdriven approach to promoting BIM implementation (Yang and Chou, 2018, Liao et al., 2019). The Development Bureau in Hong Kong have also required BIM on capital work projects worth more than HK\$30 million since January 2018. In Australasia, Australia intended to mandate the use of BIM earlier. In 2012, a national BIM initiative was prepared by buildingSMART Australasia and commissioned by Built Environment Industry Innovation Council, recommending the government to require full 3D collaborative BIM for all Australian Government building procurements by July 1, 2016 (buildingSMART Australasia, 2012). 
1 Recently, a new mandate with a focus on infrastructure commissioned by the Queensland

2 Government also took effect (Queensland government, 2018b).

$<$ Insert Table 2 here $>$

\subsection{Roles of the government in BIM adoption}

When promoting a novel approach or technological innovation for implementation, government usually plays a role in advancing the process with visible or invisible efforts (Devine-Wright, 2010). As such, the role of government in the diffusion of innovative technology receives much research interest. For instance, Shi et al. (2008) conducted a survey on cleaner production implementation in China and found that the most important role of government is supervision, followed by financial support, and technical support. Similarly, based on a case of Lithuania, Tvaronavičienè et al. (2007) investigated the implementation of innovations and concluded that providing investment, education and regulation are the most important government roles. Mistry (2005) also recognized the important role of government in bridging the gap between people who have access to information and communication technology (ICT) and those who do not. Direct and indirect government roles are also observed in these studies. Direct roles include providing subsidies or aid to stakeholders and establishing specific programs or investments to involve relevant stakeholders. Indirect roles are related to providing policies and regulations to create an environment which enables innovation.

Similarly, the government is believed to play an important role in advancing the BIM adoption. For example, Wong et al. (2009b) compared the roles of the public and private sectors in the successful BIM implementations in various countries. They concluded that the active role of the government is a driving force for achieving a high BIM adoption level. This could be because the support of the government enables an environment for uniform and consistent legal jurisdictions, education, and research and development (R \& D) in BIM. Wong et al. (2011) conducted a literature review on BIM initiatives taken by the governments of Hong Kong and the US. They concluded that the government plays a critical role in the BIM implementation in any country. For a few countries such as Finland, Norway, Denmark, and Singapore, the government can be a major driver, as discussed by Wong et al. (2009b). In contrast, for an open economy such as Hong Kong, where the private sectors are major contributors and drivers of the economy, the government is more likely to act as a regulator that controls the implementation of BIM (Wong et al., 2011). Furthermore, Cheng and Lu (2015) performed a systematic analysis on the potential roles of the government in BIM adoption based on a review of the efforts of the public sector (the government and non-profit organizations) in 14 countries across four regions: America, Asia, Australasia, and Europe. Six potential roles of the government for BIM adoption are summarized, namely, initiators and drivers, regulators, educators, funding agencies, demonstrators, and researchers (Cheng and Lu, 2015). The definition/activities of each role are given in Table 3, which will be adopted to analyze the roles of the government in the BIM adoption.

\section{$<$ Insert Table 3 here $>$}

However, these studies often overlooked the changing role of government during the whole process of the diffusion of innovation. As Lin (1993a) proposed, the penetration of information technology is a process subject to the changing roles of public and private sectors. Government acts as the primary driving force in the "take-off" stages. In later stages, government loses the dominant role and the importance of industry increases. Similarly, Lee (1988) looked at the 
1 role of government in promoting science and technology and identified the roles of Korean 2 government to be regulator, investor, and researcher. It is also found that along the process, the 3 Korean government changes its role from direct and active engagement (e.g. investor) to 4 indirect engagement (e.g. researcher).

\section{Method}

A six-step review method recommended by Jiang and Wu (2019) is adopted in this study. Defining the review scope is the first step. The aim of this review is to investigate the BIM implementation journey of three benchmark countries, namely, Singapore, the UK, and the US. All the review processes are focusing on this aim. There are three reasons for the selection of the three countries. First, all three countries have high BIM adoption level and BIM mandating experience (Yang and Chou, 2018, Wee, 2015). In addition, the UK is considered as a leading country for mandating BIM implementation, and Singapore and the US are considered to be typical successful countries that have adopted the government-driven approach and industrydriven approach in BIM implementation, respectively (Yang and Chou, 2018). Furthermore, the three countries have a clear and mature BIM journey which have been investigated by many studies and publications, e.g., reports, news and blogs. These materials provide rich and reliable information of government efforts, such as published standards, mandating polies, and established BIM institutions and BIM implementation phases.

The second step is to identify relevant literature and documents though pre-defined searching strategies, i.e., data sources and key words. All data about these three countries are collected through academic articles obtained from google scholar, authorized reports and news retrieved from google search engine, and official websites of the governments and relevant authorities. All journal articles, conference articles, book chapters, and authorized documents such as reports and standards are included in this review. In addition, key words such as "building information modeling" OR "BIM" AND "implementation" OR "diffusion" OR "promotion" AND "government" OR "roadmap" OR "government role" are used to retrieve such data.

Following these strategies, the next two steps, i.e., data collection and quality evaluation are performed to collect and screen relevant and authorized articles and documents. Data analysis is the fifth step. Text analysis is performed based on the six potential roles of the government for BIM adoption proposed by Cheng and $\mathrm{Lu}$ (2015), as demonstrated in Table 3. Based on this, results interpretation (the last step) is conducted. For example, how government efforts change overtime is investigated. In addition, a roadmap is proposed to provide step-by-step guidance on how the governments from countries with low BIM adoption rate can increase BIM adoption, by making suitable efforts at the right time.

\section{BIM implementation journey in three benchmark countries}

\subsection{BIM journey in Singapore}

\section{4.1.1 First BIM roadmap in Singapore}

The Singapore BIM journey began in 2010 when the Building and Construction Authority (BCA) of Singapore developed its first BIM roadmap (2010-2015) to drive the BIM use to 80\% in the construction industry by 2015 (Takashi et al., 2016). The roadmap highlighted the challenges of BIM adoption and put forward five strategies accordingly, namely, public sector taking the lead, regulatory approvals, removing impediments, building BIM capability and capacity, and incentivizing BIM adopters (Wee, 2015). 
To implement the first strategy, i.e., public sector taking the lead, the BCA decided to cooperate with government procurement entities (GPE) to use BIM on public projects. From 2010 to 2012, BIM was used on a few pilot projects (Shen et al., 2016). For this purpose, three BIM esubmission guidelines were released by the BCA in 2010 to pilot sites to support architectural, structural, and mechanical, electrical, and plumbing (MEP), respectively (Fatt, 2013). In 2012, GPE stipulated BIM as part of the public sector building project procurement and BIM began to become part of the regulatory approval. In 2013, BIM became mandatory for architecture submissions for all new building projects with a gross floor area (GFA) of more than 20,000 $\mathrm{m}^{2}$. This requirement was expanded to engineering submissions in the following year. In 2015, both architecture and engineering submissions were required to use BIM for all new building projects with GFA of more than $5000 \mathrm{~m}^{2}$ to reach the $80 \%$ goal (Wee, 2015). To incentivize practitioners, the BCA also provided BIM funds to qualified firms and projects since 2010 (BCA, 2015a). The aim is to defray $50 \%$ of their supportable cost, capped at $\$ 20,000$ per application and $\$ 35,000$ per discipline, respectively (Fatt, 2013, BCA, 2015b). In this process, the BCA acted as an initiator and driver. As a supplement, the roles of demonstrator and funding agency were also undertaken by the BCA to encourage more participants from the industry.

Meanwhile, to regulate the BIM mandating process, the BCA also fulfilled the regulator's work. Table 4 lists the set of BIM guidelines (e.g., Singapore BIM Guide and BIM Essential Guide series) released by the BCA to provide comprehensive guidance on BIM application, such as BIM execution plan, roles and responsibilities, BIM deliverables, BIM process, BIM quality assurance, and ownership and rights of BIM models and deliverables. The BIM Essential Guide series also provided detailed guides on good BIM practices for each discipline, including architectural consultants, contractors, civil and structural consultants, and MEP consultants. In addition, an industry-led BIM steering committee was formed during this period to provide guidance on the development of the BIM guides and how to use these guides. Its functions also include dealing with potential BIM impediments. With the committee's leadership, BIM conferences and forums were regularly held and success stories were promoted (Wee, 2015). In addition, to build BIM capabilities and capacities, the Center for Construction IT (CCIT) was established in 2010. As an educator, it provided BIM education such as training courses, outreach programs, and BIM modeling skill certifications during the whole BIM mandating process (Fatt, 2013).

\subsubsection{Second BIM roadmap in Singapore}

In 2016, Singapore launched the second BIM roadmap (2016-2020) and shifted the focus to BIM for facility and asset management, accelerating process transformation, and BIM R \& D and innovation (Hadzaman et al., 2015). Therefore, five new strategies have been developed: BIM for facility management and smart city, driving BIM collaboration throughout virtual design and construction (VDC), BIM for design for manufacturing and assembly (DfMA), new training programs at all levels, and R \& D (Wee, 2015, Shen et al., 2016). To implement these strategies, a new BIM e-submission code and BIM guides for DfMA, VDC, and asset information delivery have been issued sequentially. With the shift of focus to facility and asset management, the government plays a more important role of researcher in this phase, by listing R\&D as one of the five key strategies for BIM implementation. Table 4 also indicates that its roles as an educator is more prominent and the role as a regulator is still important during this period. 


\subsection{BIM journey in the UK}

2 Similar to that in Singapore, the BIM journey in the UK is driven by the central government. 3 In 2011, as an initiator, the UK government published the Government Construction Strategy 4 (GCS 2011-2015). This strategy mandated fully collaborative 3D BIM (i.e., BIM Level 2) for However, different from Singapore where the BCA takes most of the responsibility for promoting the use of BIM, the BIM adoption in the UK is supported by multiple specialized groups established and managed by the central government. These groups have played different critical roles of the government in different phases of BIM adoption in the UK. As such, special attention was given to the role of these groups in the development of the mandatory use of BIM in the UK. The BIM journey of the UK is summarized in Table 5.

\subsubsection{Government Construction Strategy 2011-2015}

\section{Construction Project Information Committee (CPIC)}

The Construction Project Information Committee (CPIC) is an advisory group which provides best practice guidance on content, form and preparation of construction information, and disseminating information throughout the industry. Despite that CPIC was setup early, it is still an important regulator for latter UK BIM adoption. The committee released the Uniclass and CPIC code which is fundamental for many BIM standards such as BS-1192 series. Besides, after the BIM mandating in 2011, the CPIC further released several assessment forms, such as the CPIx resource assessment form and the CPIx BIM assessment form, that help BIM users to assess their IT resources when implementing BIM hardware and software (Wu et al., 2017).

\section{BIM Task Group (BTG)}

The BTG was set up in 2011, supported by the department of Business Innovation and Skills (BIS) and the Construction Information Council (CIC). The BTG is one of the most wellknown BIM groups and the critical enabler to achieve BIM Level 2. The BTG played two critical roles, i.e., regulator and initiator.

First, the published several BIM relevant standards to provide guidance for industry partners on how to produce, exchange, and use information in the BIM. Typical examples include BS1192:2007, which provides a naming convention for BIM components; BS1192-2:2013 and BS1 192-3:2014, which specify data requirements for design and construction and for operation and maintenance (O\&M), respectively; and BS1192-4:2014, which provides a method for exchanging BIM data with COBie (BSI, 2007, BSI, 2012b, BSI, 2014a, BSI, 2014b). Most of the standards have now been collectively managed by the BSI. Besides technical standards, as a regulator, the BTG also made its contribution by proposing standard procedures to help industry users work with BIM. The typical ones are the Plan of Works (PoW) and the Government Soft Landings (GSL) (Office, 2016). The development of the PoW began at 2011, which enables definition of deliverables at each stage of a project, by providing guidance on specifying critical aspects of BIM deliverables, such as data needs, level of details (LOD) for graphical information and level of information (LOI) for non-graphical information. The PoW can facilitate a common understanding of BIM deliverables among stakeholders and in turn the assignment of roles and responsibilities (Baratono et al., 2016). In 2015, the PoW was digitalized and encapsulated in the BIM toolkit. On the other hand, the GSL was released at 2012, with the joint efforts from the BTG and the Government Property Unit. The GSL aims 
1 to, after project delivery, ensure the compliance of built asset with client's demands and

2 improve asset performance. The GSL proposes standard procedures to involve asset end users 3 and operational teams in early construction and design stages to set operation targets, as well 4 as conducting Post Occupancy Evaluation (POE), i.e., collecting asset performance data and 5 comparing with expectations. BIM will be used to store and share all expectations, asset 6 performance, POE results and feedback data (Office, 2016).

Second, the BTG is also an initiator and driver for establishing two BIM groups. The first one is the "BIM4 Groups," which are specialized groups responsible for more than 20 BIM aspects, such as BIM for public housing, BIM for modular design, and BIM for highway construction. These groups support BIM users in certain domains by various methods, including organizing forums, providing advice, and establishing BIM cases database. The second one is the "BIM Regions," which are local BIM hubs. They ensure that there is communication between the BTG and local region to disseminate latest requirements from the central government and collect feedback from local BIM users. In addition, they serve as local networks to provide timely technical and managerial support for local BIM users (Anne et al., 2018). In addition, the BTG also works with several public organizations.

\section{BIM Technologies Alliance}

The alliance was an independent non-product group setup at 2011, which represents BIM software industries by including a wide range of software vendors for the AEC market. The alliance for one thing is a BIM researcher which develops advanced technologies and data content, as well as proposes industry protocols and procedures that support interoperability between stakeholders and facilitate the adoption of BIM Level 2. For another, the alliance is also a BIM educator which provides technical advice and assistance to BIM users to embed existing BIM products in their daily work. Since 2016, the alliance has been reconstituted as a group managed by the UK BIM Alliance introduced latter (Kemp et al., 2018).

\section{BIM 2050 Group}

The BIM 2050 Group was established by the CIC at 2012. Unlike the BTG and the BIM Technologies Alliance that organize forums and workshops to provide advice and help to BIM users, the BIM 2050 group is more like a researcher. Specifically, the group has the following tasks: 1) reviews development of BIM in the UK; 2) identifies future BIM trends; 3) invite BIM professionals to brainstorm strategies and frameworks to further implement BIM, which currently includes four work streams, i.e., BIM skills, education, process and procurement and market; 4) disseminate knowledge the group gains, usually through forums, to the industry and the government (HM Government, 2013).

\section{UK Contractors Group (UKCG) and Construction Products Association (CPA)}

The two groups reflect the efforts to streamline the information flow along the supply chain of a project. The UKCG was an association of contractors and their supply chain partners. The group assists the BTG to collaborate with stakeholders along the supply chain to use BIM to store and deliver products data. In 2015, the UKCG was merged into the Build UK institution. CPA was setup at 2000 and is an important group of UK construction products manufacturers. CPA works with the BTG to ensure that off-site building products data is available for design and construction and that operational data can be fed back to manufacturers (CDBB, 2018). 
1 In 2016, the UK government published the Government Construction Strategy (GCS 20162 2020), another significant step toward BIM Level 3 that allows stakeholders to closely 3 collaborate using a single shared model held in a centralized repository and extends BIM into 4 the operation of assets over their lifecycle (Cabinet Office, 2016). For this purpose, additional 5 five groups were established to consolidate the previous achievements of BIM Level 2 and plan 6 for the future of BIM Level 3.

\section{$7 \quad$ Public Sector BIM Working Group (PSBWG)}

8 In 2016, the PSBWG was set up, aiming at continuously supporting the transition to BIM Level

92 in government departments, considering the different work procedures in these departments.

10 The role of the PSBWG is as BIM demonstrator and such role includes developing tools for

11 BIM benefits assessment, periodic reporting of BIM adoption, and case studies demonstration.

\section{UK BIM Alliance (UKBIMA)}

13 The UKBIMA, set up in 2016, aims to promote BIM implementation in both public and private sectors in the construction industry and to make BIM Level 2 "business as usual" for the private sector by 2020. The UKBIMA is another BIM demonstrator, which focuses on presenting BIM benefits to all companies. Moreover, it takes the responsibilities from the BTG to manage the "BIM4 Groups", "BIM Regions" and BIM Technologies Alliance. The UKBIMA also plays the role of a BIM educator by operating the BIM Academic Forum, which promotes the training, learning, and research of BIM in under- and postgraduate education to increase the supply of BIM professionals (Hooper, 2015). In 2017, the UKBIMA was merged with the buildingSMART UK, an international organization for encouraging BIM implementation.

\section{Center for Digital Built Britain (CDBB)}

In 2017, the CDBB was established. The BTG was terminated upon completion of its task and the CDBB will play the key role of achieving BIM Level 3. In general, the CDBB will expand the previous work from applying BIM functions (e.g., 3D visualization and 4D simulation) to information management (e.g., information storage, sharing, and utilization between all parties), from construction projects to smart city, from vertical buildings to infrastructure projects, and from the national level to the international level (Allmendinger and Sielker, 2018).

To achieve its ambition, the CDBB takes on four responsibilities. First, as a BIM demonstrator, the CDBB collects BIM best practices by setting up a digital library of BIM cases, develops tools to measure and quantify BIM benefits, and regularly organize BIM events such as workshops to allow BIM users to share their experience and get advice. Second, as a regulator, the CDBB publishes standards for information management interoperability such as the recently released Gemini Principles and the ISO 19650 - Information Management Using BIM. It also updates existing standards by collaborating with national and international bodies. Third, as a BIM educator, the CDBB develops e-training modules for high-level decision makers, middle-level managers, and operation-level BIM users to increase their BIM awareness and improve their skills. Finally, as a BIM researcher, the CDBB has three roles: 1) to develop networks for researchers to collaborate and share achievements; 2) to launch programs to fund BIM studies, such as the Mini-projects and the early career research funds; 3 ) to make research efforts particularly in two areas, which are the digital twin, a detailed digital representation of a physical asset with real-time data about its condition and usage, and the DfMA, which focuses 
1 on optimizing building design to improve efficiency during manufacturing and assembly in

2 off-site construction projects (Neely, 2019)

\section{Construction Innovation $\mathrm{Hub}$ (CIH)}

4 The CIH was setup at 2018, which is a R\&D institute granted with 72 million pounds to bring 5 together expertise from the CDBB, the Manufacturing Technology Centre (MTC), and the 6 Building Research Establishment (BRE). The MTC is a UK institute that develops innovate 7 manufacturing technologies for various industries, including construction, and the BRE is an 8 international multi-disciplinary organization that aims to improve buildings and infrastructure 9 by research. As such, the $\mathrm{CIH}$ is a BIM researcher focusing on off-site manufacture for 10 construction with two major goals. One is to develop and commercialize manufacturing and digital technologies to better combine BIM with off-site projects. The other is to understand how the industry must change in terms of personal skills, organization capacities and working process, and product standards, to create security-minded frameworks that will underpin future off-site built environment (Neely, 2019).

\section{Home Nations Working Group (HNWG)}

The BIM groups in the UK have already published approximately 32 standards and guidelines that are directly related to BIM (Eadie et al., 2015, Auodesk, 2016, Bradley et al., 2016). To encourage the implementation of these standards, the HNWG was set up in 2018. The HNWG serves as an educator for the UK BIM users. This group will help BIM users at the initial level to implement suitable BIM standards according to their business modes. For those with BIM experience, the group will help users by accelerating the transition from the standards that those companies already implemented to the newly released BIM Level 3 standards. In addition, as it is easier for public buildings to adopt off-site manufacturing methods, the HNWG also plays a demonstrator role to apply BIM and off-site technologies in several public rental building projects (Shou et al., 2015).

$<$ Insert Table 5 here $>$

\subsection{BIM journey in the US}

The US is one of the earliest countries that started BIM research in the 1970s (Eastman et al., 1974). In the early stage, the government acted as an initiator to lead the AEC industry. However, it is currently encountering a slow adoption speed throughout the country. Different from the UK and Singapore, the US has its own BIM development culture: local state governments and various organizations are developing unique but separate approaches in their areas. For example, the AEC industry wants to treat every project as a distinct challenge, where only one standardized BIM formula could not be satisfied by every agency (Pollock, 2018). In addition, the federal polity causes policy decentralization, which means that there is no such collaboration agency or organization to manage them all. As the local government works in isolation, the impact of BIM mandates or working groups is generally limited within a region. Therefore, the US chose an industry-driven, or bottom-up approach in the BIM implementation, and the main efforts of the government are to regulate the BIM practice through national and local standards/guidelines as a regulator (Yang and Chou, 2018). The term 'industry' refers to many independent industry organizations, local governments and communities.

42 The first version of ArchiCAD's file exchange solution was released in 1997, which allows

43 multiple designers to work on a collaborative platform, and it is also the first time that BIM 
1 was put into real practice in the US. As shown in Table 6, the United States General Services 2 Administration (GSA), through its Public Buildings Service Office, established the first public 3 sector leading program: the National 3D-4D-BIM Program in 2003. The GSA required that all 4 projects that used BIM should be submitted to the office for final approval if they received 5 funding in fiscal year 2007 and beyond. Meanwhile, all GSA owned projects were encouraged 6 to deploy mature 3D, 4D, and BIM technologies. After being an initiator for years, the GSA 7 started publishing BIM guidelines that were able to cover the whole lifecycle of construction 8 projects applying BIM in late 2006. Until 2017, eight series of guidelines in total have been 9 released from the office.

10 Another nonprofit agency acting as a nationwide regulator is the National Institute of Building 11 Sciences (NIBS), which works on integrating the government, industry, researchers, and 12 workers in BIM practices by a guideline. The National BIM Standard-United States (NBIMS13 US) has now developed and published its $3^{\text {rd }}$ version of BIM guideline $\left(1^{\text {st }}\right.$ version in 2009 and $142^{\text {nd }}$ in 2012), and it is also treated as the US branch of buildingSMART alliance. NBIMS-US provides generally acceptable standards by citing existing standards, documenting information exchange, and providing best project practices for the entire built environment field (NBIMSUS $\left.^{\mathrm{TM}}, 2015\right)$. In addition, it also hosted the first BIM forum to explore and deliver improvement of BIM through education and practices. Currently, the BIM forum has a wide influence in the US and conducts at least twice per year a successful demonstration to encourage more customers to use and be familiar with BIM. Moreover, NIBS also posted the first online course on the institute's newly launched Building Sciences Online Academy in 2014 in line with its role as an educator, which means that the organization has more responsibility in the BIM field compared with its previous stage (Cheng and Lu, 2015).

The national administrators or institutes are not the only entities involved in the adoption of BIM; several states, private organizations, the army, and universities are also contributing to the process. The American Institute of Architects published six series of guidelines since 2007 for the use of BIM in the design and operations of projects for architects. The Indiana University (2009), The Penn State University (2009), Georgia Tech (2011), and MIT (2016) all issued BIM standards and guidelines by their own offices, aiming to acquire leading roles in BIM adoption and implementation practices. In addition, the United States Army Corps of Engineers (USACE) recommended BIM implementation for the lifecycle operation of new construction projects using Autodesk and Bentley platforms. It also directly supported an R\&D center, which is working on exploring and applying new BIM technologies within the United States Department of Defense. Although there are some areas in the US, such as New York City, that are making their way to BIM application, the mandatory policy is much less than expected (Bloomberg et al., 2012). In 2010, Wisconsin became the first state that mandated $\mathrm{BIM}$ in all public projects with a budget of over $\$ 5$ million and new construction projects worth more than $\$ 2.5$ million. The second successful case in mandating was in 2018, when the Los Angeles Community College District set a BIM mandate for its $\$ 9.5$ billion new construction and maintenance projects across its nine campuses.

It should be noted that the focus of this research would be the role of government in promoting BIM implementation. Through the review, it is found that the US government has performed a major role as regulator, together with roles of demonstrator, educator and researcher. Although some of the departments try to drive BIM mandating, there is no national BIM mandates are initiated. It is also worth mentioning that few evidences show that any financial support has been offered by the government in the US. 


\section{$24.4 \mathrm{BIM}$ in other countries}

3 Other developed countries have also made great efforts in promoting BIM implementation. For

4 example, Finland has mandated IFC format within all the design work by the Confederation of

5 Finnish Construction Industries (He et al., 2017). In Norway, all government-led projects have

6 been using BIM across the project lifecycle. A national R\&D program to develop sustainable

7 tools for BIM has also been established (Wong et al., 2009a). Denmark produced a number of

8 technical standards on BIM modelling and IFC format, and built digital system for government

9 projects procurement and information exchange (Isak Tage Karlsson and Rönndahl, 2018).

10 France and Netherland allocated budget to support BIM research projects and companies that

11 are willing to adopt BIM (van Nederveen et al., 2010). Turkey launched several major

12 infrastructure projects, such as airports and tunnels, as cases to demonstrate BIM benefits and

13 encourage BIM use (Bastian Fuchs, 2017). The BIM journey in Germany started more than

14 fifteen years ago in some business construction companies, while the government has stepped

15 in since 2014. In 2014, the Federal Institute for Research on Building together with other

16 departments published the first "BIM-Guide for Germany", which can be considered as the

17 first step taken by German public authority. Australia government commissioned a national

18 BIM initiative in 2012 and recommended requiring full 3D collaborative BIM for all Australian

19 Government building procurements by 1 July 2016 (BuildingSMART Australasia, 2012).

20 However, nothing special happened except for some projects that adopted BIM in the next two years. One possible reason could be attributed to the isolated and inconsistent work of different States, which makes it difficult to implement a national mandate. In 2016, the Parliament of the Commonwealth of Australia released a smart ICT report, recommending mandating BIM on all government infrastructure projects costing over $\$ 50$ million (The Parliament of the Commonwealth of Australia, 2016). However, the government decided to take a slow process. On the contrary, the local states chose to move faster, especially the Queensland government. In 2017, Queensland government drafted some policies and principles on mandating BIM and released a guideline to enable BIM on road projects. In the next year, Queensland government announced the policy to mandate BIM on all government construction projects costing over $\$ 50$ million and this requirement will be expanded to all built assets by 2023 (Queensland government, 2018a).

After analyzing BIM implementation in these countries/regions, it seems that the governments only take one or two roles during the mandating phase and have not undertaken as much responsibility as the three benchmarking countries. For instance, Finland, Norway and Denmark acted as a driver and a regulator in the progress. France and Netherland performed the role as funding agencies. Turkey acted as a demonstrator in its projects. These countries, although still adopt the government-driven approach, have limited roles when compared with the three benchmarking countries.

\section{Roadmap of BIM implementation and roles of the government}

40 From the above review, it is evident that the government-driven approach was adopted in

41 Singapore and the UK, where the government takes a leading role of mandating BIM use. In contrast, the US adopted an industry-driven approach and the government is less involved in promoting BIM implementation. The roadmap of BIM implementation is shown in Figure 1. In this section, the government roles in each phase and the changing roles to implement BIM 
1 are explained. Moreover, the findings are compared with the government roles when promoting

2 other ICTs (e.g., Internet and Internet of Things (IoT)).

$<$ Insert Figure 1 here $>$

\subsection{Government-driven approach}

The government-driven approach is suitable for countries and regions where policies of the central government are easy to implement (Wong et al., 2009b, Yang and Chou, 2018). When using the government-driven approach, a phase-by-phase pattern can be observed. This phaseby-phase pattern is also observed when promoting other ICTs. For instance, the Japan government made a three-phase strategy to promote IoT, focusing on the infrastructure construction of IoT, the joint collaboration with large companies to quickly increase the adoption of IoT in different industries, and the expansion of IoT application into all public sectors, respectively (Xia, 2012). Similarly, Lin (1993b) also found a three-phase pattern when the US government promoted the internet technology. The three stages include the innovation phase which heavily relied on government funds (1969-1986), the "Take-off" phase (1987, i.e., the technology was quickly adopted by industry leaders and gained substantial awareness in a short period), and the early major adoption phase (1988-1996), where the industry accepted the technology and can make profits from it without government support.

\subsubsection{First phase: increasing the use of BIM among stakeholders}

In the first phase, the focus is on expanding BIM use as rapidly as possible to promote its awareness. For example, in the first phase, Singapore aimed to engage $80 \%$ of the local industry in BIM use during 2010-2015, while in 2011, the UK required all central government departments to achieve BIM Level 2 by 2016. As such, it is essential to ensure that several stakeholders are involved in the first phase using key strategies below.

\section{(1) Encouraging and incentivizing stakeholders}

To involve more stakeholders, the government can have multiple encouraging roles, such as initiator and driver, demonstrator, and funding agency. In this phase, it appears that the government has a dominant role as initiator and driver:

- Setting an appropriate implementation target is often the first step. For example, Singapore set the $80 \%$ goal in the first BIM roadmap and the UK set the BIM Level 2 goal in Government Construction Strategy (GCS 2011-2015). Setting goals is also a common approach that the government can take as a driver to initiate the diffusion of technologies. For instance, the Chinese government has published several goals for the period 2016-2020 to drive the modular construction technology, by specifying the percentage of buildings that should adopt the technology (Wu, 2016).

- Establishing working groups and committees is also important (Kassem and Succar, 2017). In Singapore, the BCA works as the leading authority from the very beginning. In the UK, under the central government, the BTG was established as the leading authority and the BIM4 Groups and BIM Regions were set up for specific disciplines (e.g., public housing and modular design) and local management, respectively. Similar approaches have been adopted by the US government to promote the internet, where many working groups and institutions were setup. For example, the Network Working Group was responsible for releasing standards and protocols for internet applications 
and the Network Measurement Center was responsible for assessing the performance and industry acceptance of Internet (Lin, 1993b).

- The BIM mandate is also a good driver for BIM implementation (Yang and Chou, 2018). One interesting finding is that unlike the UK which mandated BIM when the BIM goal was initially set up, Singapore mandated BIM use after two years of practice and demonstration on pilot public building projects. The public building sector is often the first choice for initiating the mandating process (BuildingSMART Australasia, 2012, Wee, 2015). For one thing, the vertical buildings are considered as ideal for BIM use (Porwal and Hewage, 2013), for another, public buildings are also easy to manage by the central or state governments (Mintzberg, 1996). Mandating is also widely applied for other ICTs. For instance, many local governments in China have mandated modular construction techniques for public buildings (Wu, 2016). The US also mandated several Internet protocols (e.g., the File Transfer Protocol and TCP/IP protocol) during the diffusion of internet technology (Lin, 1993b).

Continuous demonstration of BIM benefits and experience is also required by the two countries in this phase. This can be achieved by publications, awards, and regularly organized forums and competitions. It is suggested that such demonstration is conducted by a specific working group managed by the central government rather than the government itself. Because it is easier for the central government to set goals and monitor the holistic process while outsourcing specific tasks to specialized staff (Pirannejad et al., 2010). When promoting other ICTs, the US, France, and Korea played similar roles of demonstrator. Besides, the importance of establishing a collaboration network is also emphasized, which may provide usful reference for BIM implementation as well. Such a network can take many forms, e.g., forums and webpages. The aim is to allow companies to demonstrate their products and attract investments from the market, which can increase the awareness of ICTs and release some financial burden of the government (Gong, 2009).

Moreover, Singapore also provided BIM funds to qualified BIM projects and enterprises since the BIM mandate was established, was not the case in the UK. The BIM fund helped many firms in Singapore build up their internal BIM capability, making it easier for them to develop their BIM collaboration capability, which is the key to gain full benefits of the BIM (BCA, 2015a). Similarly, when promoting the internet technology, the US government paid particular attention to the role of funding agency. For many early companies that adopted the internet, more than one-third of their R\&D funds were provided by the government (Lin, 1993b). In addition providing funds, the US government also procured the services and products of early adopters to share their risks when promoting the internet technology (Lin, 1993b). Meanwhile, apart from direct subsidies, the governments in Japan, Korea, and several European countries (e.g., Germany, France, and Finland) tend to drive technologies by providing companies with more financial supports (e.g. tax reduction and credit guaranty) or by establishing governmentindustry-research corporation by investing on pilot projects (NRC, 1997, Gong, 2009).

\section{(2) Providing technical support and guidance}

Apart from encouraging stakeholders, technical support and guidance are also required for the stakeholders' BIM practices. Therefore, the government also works as an educator (e.g., by running training or education programs) and a regulator (e.g., by releasing standards and guidelines). The heavy involvement of the government as an educator can be demonstrated by the CCIT in Singapore, which offered various training, handholding, and outreach programs, certificate courses, and specialist diploma to stakeholders and students since 2011. 
In addition, standards and guidelines are necessary for promoting BIM implementation. The standards/guidelines in Singapore are often stakeholder-oriented and the focus is given to management aspects rather than technical details. In this phase, the sequence of releasing standards generally follows the lifecycle of buildings, i.e., planning, design, and construction, and some examples are listed below:

- 2010-2011: During the first two years' pilot projects, three BIM e-submission codes were developed for pilot architectures, structural, and MEP with a focus on the design stage.

- 2012 (the same year of the first BIM mandate in Singapore): Singapore BIM Guide Version 1.0 (BCA, 2012) applicable to all stakeholders was released to provide guidance on management issues including BIM execution plan, BIM deliverables, LOD, BIM objectives and responsibility matrix, and modeling and collaboration procedures. A sample of the BIM particular conditions was also appended to deal with contractual issues.

- 2013-2015: As Singapore BIM guide only provides general and universal requirements for BIM implementation, a series of essential guides for different specific disciplines were released (Table 4).

In the UK, things are different. One feature of the released standards is that particular attention is given to data exchange between stakeholders and between project stages by standardizing modeling manner. Less consideration is given to BEP, stakeholder responsibilities, and BIM implementation process for stakeholders. A possible reason leading to the difference could be the different visions of these two countries. Singapore aims to promote BIM implementation among stakeholders and boost productivity in the AEC sector. The UK, on the other hand, although has similar goal of promoting BIM implementation, also aims to be the world leader of BIM related technologies. As such, standards of information exchange, one critical issue in BIM implementation, can be better adapted to other countries because such technical issues on information exchange are generally and consistently faced by all other countries (Alreshidi et al., 2017). Another feature of the UK is the early consideration of O\&M stage, which is earlier than most countries including Singapore and the US. Below are some examples:

- 2012: BS 8541-1, 3, and 4 (BSI, 2012d, BSI, 2012a, BSI, 2012c), which defined the format, contents, LOD, shape, and naming conventions of BIM objects as a foundation of information exchange for lifecycle use and management, were released.

- 2013: ISO 16739 (ISO, 2013) was released to provide guidance on data sharing for both construction and facility management companies using IFC.

- 2014: PAS 1192-3 and 4 (BSI, 2014a, BSI, 2014b), which focused on management in O\&M and information exchange requirements using COBie, respectively, were released.

- 2015: The Uniclass 2015 (NBS, 2015), which was a standard classification of building components to serve as a baseline of BIM-based collaboration, was released.

The combination of the standards published by the two countries may contribute to a complete framework of BIM standards for buildings in this phase. In addition, the role as a regulator (i.e. publishing standards) is observed in all countries when promoting ICTs, e.g., the IoT standards published by the US and Europe (Xia, 2012) and the Internet protocols/standards published by the US (Lin, 1993b). Moreover, the governments also published several laws to protect the 
1 intelligent patents (IP) of new ICTs and regulate their use in business. Such efforts are less

2 addressed for BIM possibly because BIM is not a fundamental innovation but an application

3 (i.e. many technologies required by BIM are already protected by IP laws). Nevertheless, as

4 many studies recognize that standard BIM contracts are important for BIM implementation in

5 projects, it is necessary that the governments pay more attention to this aspect (Chong et al.,

6 2017).

\section{$7 \quad$ 5.1.2 Second phase: expanding the use of BIM to a higher level}

8 In the second phase, as BIM has already been widely recognized and adopted, the BIM

9 capabilities of the stakeholders have been built up. Thus, the priority of implementation is

10 gradually shifted from stakeholders' involvement to a higher-level BIM implementation (e.g.,

11 expanding the BIM coverage from the building sector to the smart city level and improving the

12 extent of BIM use from Level 2 to Level 3). For instance, in the second BIM roadmap (2016-

13 2010), Singapore aims to expand BIM adoption from conventional buildings to manufacturing

14 and assembly, facility management, and smart city (Wee, 2015). Similarly, the UK aims to

15 extend BIM from the public buildings to all buildings and infrastructure projects and smart city.

16 Furthermore, to improve the extent of BIM use, the UK is also determined to achieve Level 3

17 BIM from 2016 to 2020 (Cabinet Office, 2016).

(1) Encouraging and incentivizing stakeholders

As the market becomes mature, the encouraging roles of the government (especially the initiator and driver) becomes less important in the second phase. This can be evidenced by the fact that no new BIM mandates were released in the second phase in both Singapore and the UK, which is a significant difference compared to the first phase. Similar pattern is also observed when promoting other ICTs. For instance, when implementing the internet technology, most standards (e.g. TCP/IP and E-mail protocols) were mandated by the US government at the first phase (Lin, 1993b). It should be noted that BIM demonstration was not highlighted in Singapore in this phase, while much efforts were made to demonstrate BIM cases and benefits in the UK. Similarly, the Singapore government paid less attention to fund BIM users after 2018 (see Table 4), whereas the UK setup new funds to promote BIM (Table 5). The reason could be that Singapore achieved the $80 \%$ goal while the UK still needed to involve more practitioners from the private sector (Cabinet Office, 2016).

\section{(2) Providing technical support and guidance}

Technical support roles such as educator and regulator become more important in this phase. First, more BIM-related studies are launched by the government, which can be reflected by the additional R\&D programs and research funds in Singapore and UK (Table 4 and 5). Second, more attention is paid to the role of an educator. Specifically, Singapore set new training programs for practitioners at all levels as one of the five strategies in the second BIM roadmap. A BIM e-learning module was also developed in the UK to enable online BIM learning for employees at all levels. In addition, when BIM adoption gradually extends to various sectors (e.g., off-site construction, infrastructure and energy projects) and to more project phases (e.g. O\&M), publishing relevant standards as a regulator is still important to guide BIM users in these areas. In Singapore, BIM standards/guidelines are extended from the design and construction stage to the O\&M stage. The scope is also extended from conventional buildings to manufacturing and assembly and to facilities: 
- 2016: BIM for DfMA (Design for Manufacturing and Assembly) Essential Guide (BCA, 2016) was released with an aim of changing the construction methods by integrating BIM and DfMA.

- 2018: BIM Guide for Asset Information Delivery (BCA, 2018) was released to enable building/facility owners to use BIM for O\&M.

Similarly, in the UK, newly published standards aim to increase the scope of BIM to go beyond the conventional building sector and reach a smart city scale. Besides, a BIM Level 3 is also targeted, where the essence is to build a fully collaborative platform for information sharing between various stakeholders. Below are some examples:

- 2015: BS 8541-5 and 6 (BSI, 2015b, BSI, 2015a), which reflected the shift from conventional buildings to off-site construction and modular buildings, were released.

- 2018: The Gemini Principles (CDBB, 2018) was released to propose an information management framework that enables interoperability (BIM Level 3) across the entire built environment.

The increasing importance of supporting roles is also observed in the diffusion of other ICTs. For instance, despite of the large R\&D investment of internet technology in the first phase, the R\&D funds in 1996 was ten times higher than the initial investment in 1988 (Lin, 1993b). One finding is that as a researcher, many governments in this phase also conduct research at both technological and marketing aspects (e.g. the demand and degree of match between the technology and the market), to keep expanding the application areas of the technology (NRC, 1997, Jon, 1999). This is less observed when promoting BIM, where the market uptake is often completed by companies (e.g., Autodesk) (McGraw-Hill, 2012, Auodesk, 2016).

Based on above discussion, when promoting BIM and other ICTs, the main pattern and principles of technology diffusion are similar, namely, the government plays essential roles (especially driver and initiator) to drive early implementation of the technology. However, when the technology is gradually recognized and adopted by the industry, the government should pay more attention to the supporting roles (e.g., researcher, educator, and regulator) to regulate the market, assist the new adopters, and expand the application areas of the technology.

\subsection{Industry-driven approach}

Different from Singapore and the UK, the US adopted the industry-driven approach, where the US government is relatively less active. The industry-driven approach is more applicable to countries with federal systems and/or open economies where the policies of the central government are difficult to implement nationally and the market force can be dominant (Andy K. D. Wong et al., 2011).

Because of the federal system, each state government works independently and there is no national BIM mandate, education programs, R\&D programs, or BIM funds in the US. However, a similar BIM implementation path can be observed by investigating one specific government authority (e.g., the GSA).

The most important role of the US government is regulator, i.e., regulating the BIM practice of the industry by standards and guidelines. The US has released the greatest number of standards among the three countries, which confirms the findings of the research by Shou et al. (2015). Of interest is that different from Singapore or the UK where the BIM standards are generally 
released by governmental authorities, the majority of BIM standards in the US are released by research centers or institutions. In addition, different states generally develop and use their own standards, for example, the State of Wisconsin developed its unique guidelines for projects released within the state in 2012. Therefore, the BIM standards in the US are disperse and inconsistent (Smith, 2014b). This may cause risks in practice because practitioners in the supply chain can be confused by the different requirements, leading to difficulty in cooperation. This could be one of the reasons why BIM implementation in the US is slowing down (Null, 2018).

Although it is difficult to extract a clear path of BIM implementation in the US due to the inconsistent efforts of different states and authorities, the GSA is often specifically mentioned when government efforts are investigated. This is because the GSA is the prime government authority promoting BIM, which has gained successful achievements in the US (Wong et al., 2011, Cheng and Lu, 2015). The first step made by the GSA was to establish the national 3D4D BIM program through its Public Building Service in 2003. For the program, 200 projects valued over $\$ 12$ billion were successfully implemented with the use of BIM (Cheng and Lu, 2015). In 2007, the GSA required an IFC-based BIM for all FY07 projects, which was the first BIM mandate in the US. One of the highlights of the program is that a series of BIM guides were published along the program ongoing. As one of the largest building owners, the GSA placed the focus on buildings and developed the standards following the lifecycle stages:

- 2006-2007: Before the mandate, GSA BIM Guide Series 01 and 02 (GSA, 2006, GSA, 2007) were available. These were meant to provide background information and requirement of the program as well as best practices for design and construction teams.

- 2009: The GSA BIM Guide Series 03 and 04 (GSA, 2009a, GSA, 2009b) were published to describe the processes of executing 3D imaging and 4D schedule management, with a focus on the design and construction phases of buildings.

- Since 2011: Since the publication of Series 08 (GSA, 2011), the GSA BIM Guide began to take infrastructure into consideration and extended the focus from the design and construction phases to the whole lifecycle of buildings.

The standards can not only be used in GSA projects, but also provide a fundamental framework for a nationwide BIM implementation. One evidence is that most standards/guidelines released by research centers or institutions are developed based on the GSA BIM series and the National BIM Guideline (NBIMS-USTM, 2015). By integrating knowledge in these national standards and specific application fields and objectives, the local institutions can develop the standards that best suit their needs. This strategy can provide reference to other countries or regions that follow the industry-driven approach in practice. It is recommended that states or organizations develop their guidelines and/or policies based on internationally/nationally or widely accepted practices. This can help reduce conflicts between each guideline and improve the consistent awareness of BIM in their areas (Cheng and Lu, 2015).

It turns out that both approaches encourage BIM use in the design and construction of public buildings. BIM implementation is then extended to the whole lifecycle of buildings, as well as other facilities (e.g., from public buildings to private buildings, from conventional buildings to modular buildings, and from buildings to infrastructure projects) and even smart city. It should be noted that although many countries start BIM implementation in the building sector, it is not always the best option. A typical example is Australia, which is seen to be highly driven 
1 by infrastructure (Paul, 2018). One possible reason could be the relatively low demand for

2 high-rise buildings due to its low population density (Population Australia, 2019).

3

4

5

6

7

8

\section{Conclusion}

BIM is recognized by the AEC industry in many countries. However, there are significant disparities between the levels of awareness and implementation. The government is believed to play a critical role in BIM implementation, but most countries still lack experience with it. This study investigates the BIM implementation journey of three benchmark countries, namely, Singapore, the UK, and the US, to reveal the regular pattern of BIM adoption and the roles of the government. The findings show that Singapore and the UK apply a government-driven approach whereas the US adopts an industry-driven approach. For the first two countries, a phase-by-phase development is observed. In the first phase, the BIM is mandated in one specific area (e.g., the building sector) and the dominant role of the government is initiator and driver, which is good for expanding the use of BIM rapidly. In this phase, the roles of a demonstrator (promoting success stories) and a regulator (releasing standards and guidelines) are also important to engage the industry and to remove the impediments that may be encountered. Demonstration can be carried out through publication, awards, and regularly organized forums and competitions. In addition, the standards are recommended to be released in a consistent way to provide practical guidance on BIM implementation, such as the modeling methodology, stakeholder responsibilities, implementation processes, collaboration procedures, and contractual issues. In the second phase, BIM has been gradually accepted by the market and expanded to other areas (e.g., asset management, infrastructure and smart city) and to a higher level (e.g., from Level 2 to Level 3). It is found that, in this phase, governments pay less attention to the role of initiator and driver. More attention is paid to supporting roles (i.e., educator, researcher, and regulator) to guide BIM users in different disciplines and promote BIM to higher technical maturity. Varied patterns are observed when the governments adopt encouraging roles (i.e., funding agency, and demonstrator), depending on the outcome of the first phase implementation. Besides, for the US, as different states have their own autonomy, it is difficult to have a consistent BIM adoption goal or mandate. Institutions and research centers often play an important role and the government generally acts as a regulator. However, a specific authority such as the GSA can advance BIM implementation following a similar path as Singapore and the UK. It should also be noted that although these three countries all began the application of BIM in the building sector, for other countries where the demand for buildings are low (e.g., Australia), the building sector may not be the best choice.

This study discusses the suitability of government-driven and industry-driven approaches for promoting BIM in countries with different characteristics. Step-by-step BIM roadmaps are proposed for the two approaches, respectively. The roadmaps provide details on what kinds of efforts can be made, including government and industry leadership. They also provide details on the priority related to when to make such efforts to promote to use of BIM. In addition, the implementation strategies are presented in detail so as to guide the BIM implementation of other countries. For example, a framework of the BIM standards to be released is proposed, including both the theme of each standard and their sequence. With the roadmaps proposed in this paper, the governments of other countries can select an appropriate BIM diffusion method and follow the steps and government roles to gradually increase the adoption of BIM. It is recommended that the BIM diffusion method is carefully selected based on the countries' own contexts (e.g., government force on policy implementation). In addition, BIM acceptance and maturity need to be considered before taking real actions for the benchmarking (Lee and $\mathrm{Yu}$, 2016, Kassem and Succar, 2017). 
1 It should also be noted that only three countries were analyzed in this study; therefore, other 2 patterns may not be captured, for example, a hybrid approach. Future studies can include more 3 countries and jurisdictions, such as Denmark, the Netherlands, Norway, Japan, Hong Kong, 4 and Taiwan. In addition, this study did not discuss the role of industry participants in promoting

5 the use of BIM, which can be investigated in future research.

\section{Acknowledgments}

7

The funding information is removed at this stage for blind review. The funding information will be added at a later stage.

\section{Declarations of interest: none.}

\section{References}

Allmendinger, P. \& Sielker, F. 2018. Centre for Digital Built Britain Mini-projects Programme 2017-18 Urban Planning and BIM Final Report. Cambridge, UK: University of Cambridge.

Alreshidi, E., Mourshed, M. \& Rezgui, Y. 2017. Factors for effective BIM governance. Journal of Building Engineering, 10, 89-101.

Anne, K., Martin, P., Pam, B., Stephen, H., Rick, H. \& David, G. 2018. UK BIM Alliance Annual Report 2018. London, UK: UK BIM Alliance.

Atkinson, L., Amoako-Attah, J. \& B-Jahromi, A. 2014. Government's influence on the implementation of BIM. Computing in Civil and Building Engineering (2014).

Auodesk 2016. Autodesk and the UK BIM Level 2 Mandate. Autodesk, UK.

Baratono, P., Cirbini, A., Bew, M. \& Blackwell, B. 2016. Handbook for the Introduction of Building Information Modelling by the European Public Sector. EU BIM Task Group.

Bastian Fuchs 2017. BIM Status of Implementation in Germany. 2017 Annual Conference of the European Society of Construction Law. Switzerland.

BCA 2012. Singapore BIM Guide. Singapore: Building and Construction Authority.

BCA. 2015a. Building Information Model (BIM) Fund V2: Now firms can get more help to build up BIM collaboration capabilities [Online]. Available: https://www.bca.gov.sg/emailsender/BuildSmart062015/microsite/05 Building_Information Model (BIM) Fund V2.shtml [Accessed June 5th 2019].

BCA. 2015b. Technology Adoption: Building Information Model (BIM) Fund V2 [Online]. Available: https://www.bca.gov.sg/BIM/bimfund.html [Accessed June 5th 2019].

BCA 2016. BIM Essential Guide For DfMA (Design for Manufacturing and Assembly). Singapore: Building and Construction Authority.

BCA 2018. BIM Guide for Asset Information Delivery. Singapore: Building and Construction Authority.

Bloomberg, M. R., Burney, D. J. \& Resnick, D. 2012. New York City BIM Guidelines. In: Construction, D. o. D. a. (ed.).

Bradley, A., Li, H. J., Lark, R. \& Dunn, S. 2016. BIM for infrastructure: An overall review and constructor perspective. Automation in Construction, 71, 139-152.

Bryde, D., Broquetas, M. \& Volm, J. M. 2013. The project benefits of Building Information Modelling (BIM). International Journal of Project Management, 31, 971-980.

BSI 2007. BS 1192:2007 Collaborative production of architectural, engineering and construction information - code of practice. London, UK: British Standards Institution. 
BSI 2012a. BS 8541-3:2012 Library objects for architecture, engineering and construction. Shape and measurement. Code of practice. London, UK: British Standards Institution. BSI 2012b. COBie-UK-2012. London, UK: BIM Task Group.

BSI 2012c. BS 8541-4:2012 Library objects for architecture, engineering and construction. Attributes for specification and assessment. Code of practice. London, UK: British Standards Institution.

BSI 2012d. BS 8541-1:2012 Library objects for architecture, engineering and construction. Identification and classification. Code of practice. London, UK: British Standards Institution.

BSI 2013. PAS 1192-2: 2013 Specification for information management for the capital/delivery phase of construction projects using building information modelling. London, UK: British Standards Institution.

BSI 2014a. PAS 1192-3: 2014 Specification for information management for the operational phase of assets using building information modelling. London, UK: British Standards Institution.

BSI 2014b. BS 1192-4:2014. Collaborative production of information Part 4: Fulfilling employer's information exchange requirements using COBie - Code of practice. London, UK: British Standards Institute.

BSI 2015a. BS 8541-6:2015 Library objects for architecture, engineering and construction. Product and facility declarations. Code of practice. London, UK: British Standards Institution.

BSI 2015b. BS 8541-5:2015 Library objects for architecture, engineering and construction. Assemblies. Code of practice. London, UK: British Standards Institution.

BuildingSMART 1996. Industry Foundation Classes Version 4.2 bSI Draft Standard IFC Bridge proposed extension. Hertfordshire, UK: buildingSMART International Limited.

BuildingSMART Australasia 2012. National Building Information Modelling Iniative. Sydney: buildingSMART Australasia.

Cabinet Office 2011. Government Construction Strategy 2011-2015. London, UK: Cabinet Office.

Cabinet Office 2016. Government Construction Strategy 2016-2020. London, UK: Cabinet Office.

CDBB 2018. The Gemini Principles. London, UK: Centre for Digital Built Britain.

Chan, D. W. M., Olawumi, T. O. \& Ho, A. M. L. 2019. Critical success factors for building information modelling (BIM) implementation in Hong Kong. Engineering, Construction and Architectural Management, 26, 1838-1854.

Cheng, J. C. \& Lu, Q. 2015. A review of the efforts and roles of the public sector for BIM adoption worldwide. Journal of Information Technology in Construction (ITcon), 20, 442-478.

Chong, H.-Y., Fan, S.-L., Sutrisna, M., Hsieh, S.-H. \& Tsai, C.-M. 2017. Preliminary contractual framework for BIM-enabled projects. Journal of Construction Engineering and Management, 143, 04017025.

Dodge Data \& Analytics 2017. The Business Value of BIM for Infrastructure 2017. SmartMarket Report. Bedford, MA, USA: Dodge Data \& Analytics.

Eadie, R., Browne, M., Odeyinka, H., McKeown, C. \& McNiff, S. 2015. A survey of current status of and perceived changes required for BIM adoption in the UK. Built Environment Project and Asset Management, 5, 4-21.

Eastman, C., Fisher, D., Lafue, G., Lividini, J., Stoker, D. \& Yessios, C. 1974. An outline of the building description system. Research Rep, 50, 1974. 
Eastman, C., Teicholz, P., Sacks, R. \& Liston, K. 2011. BIM handbook: A guide to building information modeling for owners, managers, designers, engineers and contractors, John Wiley \& Sons.

Fatt, C. T. 2013. Singapore BIM roadmap [Online]. Available: https://www.cic.hk/cic data/pdf/about_cic/news and update/past event/chi/2013 11 29\%20\%20Mr\%20CHENG\%20Tai-fatt.pdf [Accessed June 5th 2019].

Georgia Tech 2011. Georgia Tech BIM Requirements \& Guidelines for Architects, Engineers and Contractors. Atlanta, Georgia, U.S.: Georgia Tech, .

Ghaffarianhoseini, A., Tookey, J., Ghaffarianhoseini, A., Naismith, N., Azhar, S., Efimova, O. \& Raahemifar, K. 2017. Building Information Modelling (BIM) uptake: Clear benefits, understanding its implementation, risks and challenges. Renewable and Sustainable Energy Reviews, 75, 1046-1053.

Gong, L. L. 2009. The Comparison Stuyd on the Mode of Technology Innovation Policy. Master, Dalian University of Technology.

GSA 2006. GSA BIM Guide For Spatial Program Validation. Washington, DC, US: U.S. General Services Administration.

GSA 2007. GSA BIM Guide Overview Washington, DC, US: U.S. General Services Administration

GSA 2009a. GSA BIM Guide For 3D Imaging. Washington, DC, US: U.S. General Services Administration

GSA 2009b. GSA BIM Guide For 4D Phasing Washington, DC, US: U.S. General Services Administration

GSA 2011. GSA BIM Guide For Facility Management Washington, DC, US: U.S. General Services Administration.

Hadzaman, N. A. H., Takim, R. \& Nawawi, A. H. 2015. BIM Roadmap Strategic implementation plan Lesson learnt from Australia Singapore and Hong Kong. 31st Annual ARCOM Conference.

He, Q. H., Wang, G., Luo, L., Shi, Q., Xie, J. X. \& Meng, X. H. 2017. Mapping the managerial areas of Building Information Modeling (BIM) using scientometric analysis. International Journal of Project Management, 35, 670-685.

HM Government 2013. Construction 2025. London, UK.

Hooper, M. 2015. Bim Standardisation Efforts - the Case of Sweden. Journal of Information Technology in Construction, 20, 332-346.

Indiana University 2009. BIM Guidelines \& Standards for Architects, Engineers, and Contractors. Indiana, U.S.: University Architect's Office, Indiana University

International Alliance for Interoperability 1999. Industry Foundation Classes IFC2x Edition 3 Technical Corrigendum 1. UK: The International Alliance for Interoperability

Isak Tage Karlsson \& Rönndahl, C. 2018. A study of National BIM guidelines around the World: Determining What Swedish National BIM Guidelines Ought to Contain. Jönköping University.

ISO 2013. Industry Foundation Classes (IFC) for data sharing in the construction and facility management industries. Geneva, Switzerland: International Organization for Standardization.

Jiang, R. \& Wu, P. 2019. Estimation of environmental impacts of roads through life cycle assessment: A critical review and future directions. Transportation Research Part D: Transport and Environment, 77, 148-163.

Jon, P. 1999. What are the Appropriate Roles for Government in Technology Deployment? Colorado, US: National Renewable Energy Laboratory. 
Kassem, M. \& Succar, B. 2017. Macro BIM adoption: Comparative market analysis. Automation in Construction, 81, 286-299.

Kemp, A., Penny, M., Bhandal, P. \& Holmes, S. 2018. UK BIM Alliance Annual Report 2018. London, UK: UK BIM Alliance.

Lee, C.-O. 1988. The role of the government and R\&D infrastructure for technology development. Technological Forecasting and Social Change, 33, 33-54.

Lee, S. \& Yu, J. 2016. Comparative study of BIM acceptance between Korea and the United States. Journal of Construction Engineering and Management, 142, 05015016.

Liao, L., Lin, E. T. A. \& Low, S. P. 2019. Assessing building information modeling implementation readiness in building projects in Singapore. Engineering, Construction and Architectural Management.

Lin, N. 1993a. Diffusion of information technology: A case study of computer network and the role of government, industry, and academia in developing the Internet/NREN.

Lin, N. 1993b. Diffusion of information technology: A case study of computer network and the role of government, industry, and academia in developing the Internet/NREN. $\mathrm{PhD}$, The University of Texas at Austin.

Lindblad, H. \& Guerrero, J. R. 2020. Client's role in promoting BIM implementation and innovation in construction. Construction Management and Economics, 38, 468-482.

Liu, S., Xie, B., Tivendal, L. \& Liu, C. 2015. The driving force of government in promoting BIM implementation. J. Mgmt. \& Sustainability, 5, 157.

McGraw-Hill 2012. The Business Value of BIM for Infrastructure. Hamilton, NJ: McGrawHill Construction.

Mintzberg, H. 1996. Managing government - Governing management. Harvard Business Review, 74, 75.

Mistry, J. J. 2005. A conceptual framework for the role of government in bridging the digital divide. Journal of Global Information Technology Management, 8, 28-46.

MIT 2016. MIT Design Standards BIM and CAD Drawing Standards v6.0. Cambridge, Massachusetts, U.S.: Department of Facilities, MIT.

NBIMS-US ${ }^{\text {TM }}$ 2015. National BIM Standard - United States ${ }^{\circledR}$ Version 3. DC, U.S.: National Institue of Buildin Science.

NBS 2015. Uniclass 2015. London, UK: National Building Specification.

NBS 2016. International BIM Report 2016. UK: National Building Specification.

Neely, A. 2019. Developing the Capabilities for a Digital Built Britain. London, UK: Centre for Digital Built Britain.

NRC 1997. Maximizing U.S. Interests in Science and Technology Relations with Japan. Washington, DC: National Research Council.

Null, S. 2018. Dear USA, the UK Is Beating You at BIM [Online]. Available: https://constructible.trimble.com/construction-industry/dear-usa-the-uk-is-beatingyou-at-bim-adoption [Accessed July 4th 2018].

Office, C. 2016. Government Soft Landings. London, UK.

Paul, S. 2018. BIM adoption around the world: how good are we? [Online]. Available: https://www.geospatialworld.net/article/bim-adoption-around-the-world-how-goodare-we/ [Accessed May 13rd 2019].

Pirannejad, A., Salami, H. \& Mollaee, A. 2010. Outsourcing priorities of government functions: Analytic network process approach. African Journal of Business Management, 4, 17231735.

Pollock, E. 2018. A Tale of Two Countries: Why the US Won't Follow the UK's Lead on BIM [Online]. Available: https://www.engineering.com/BIM/ArticleID/16959/A-Tale-of- 
Two-Countries-Why-the-US-Wont-Follow-the-UKs-Lead-on-BIM.aspx [Accessed May 17th 2018].

Population Australia. 2019. Melbourne Population 2019 [Online]. Available: http://www.population.net.au/melbourne-population/ [Accessed June 6th 2019].

Porwal, A. \& Hewage, K. N. 2013. Building Information Modeling (BIM) partnering framework for public construction projects. Automation in construction, 31, 204-214.

Queensland government 2018a. Building Information Modelling (BIM). Queensland, Australia: State of Queensland.

Queensland government 2018b. Digital Enablement for Queensland Infrastructure - Principles for BIM Implementation. Queensland, Australia: State of Queensland.

Shen, L., Edirisinghe, R. \& Yang, M. G. 2016. An Investigation Of BIM Readiness Of Owners And Facility Managers In Singapore: institutional case study. CIB World Building Congress.

Shi, H., Peng, S., Liu, Y. \& Zhong, P. J. J. o. c. p. 2008. Barriers to the implementation of cleaner production in Chinese SMEs: government, industry and expert stakeholders' perspectives. $16,842-852$.

Shou, W. C., Wang, J., Wang, X. Y. \& Chong, H. Y. 2015. A Comparative Review of Building Information Modelling Implementation in Building and Infrastructure Industries. Archives of Computational Methods in Engineering, 22, 291-308.

Smith, P. 2014a. BIM Implementation - Global Strategies. Procedia Engineering, 85, 482-492.

Smith, P. 2014b. BIM implementation-global strategies. Procedia Engineering, 85, 482-492.

Takashi, K., Shuzo, F., Atsushi, T. \& Nisi, D. 2016. Overview of BIM Implementation in Singapore and Japan. Journal of Civil Engineering and Architecture, 10.

The Parliament of the Commonwealth of Australia 2016. Smart ICT Report on the inquiry into the role of smart ICT in the design and planning of infrastructure.

The Penn State University 2009. Building Information Modeling Execution Planning Guide. Pennsylvania, U.S.: Office of Physical Plant, The Penn State University, .

Tvaronavičienè, M., Korsakienè, R. J. B. T. \& Practice 2007. The role of government in implementation of innovations: a case of Lithuania. 8, 9-13.

US Army Corps of Engineers 2007. Construction Operations Building Information Exchange (COBIE). Champaign, US: US Army Corps of Engineers.

van Nederveen, S., Beheshti, R. \& Willems, P. 2010. Building Information Modelling in the Netherlands: A Status Report. CIB World Building Congress. London, UK.

Waterhouse, R. \& Johston, J. 2018. National BIM Report 2018. London, UK: National Building Specification.

Wee, T. K. 2015. Singapore BIM journey [Online]. Available: http://www.pujabrunei.org/pdf/2015/BIM\%20Roadmap\%20Nov\%206.0.pdf [Accessed June 5th 2019].

Wong, A., Wong, F. K. \& Nadeem, A. Comparative roles of major stakeholders for the implementation of BIM in various countries. Proceedings of the International Conference on Changing Roles: New Roles, New Challenges, Noordwijk Aan Zee, The Netherlands, 2009a.

Wong, A. K. D., Wong, F. K. \& Nadeem, A. 2009b. Comparative roles of major stakeholders for the implementation of BIM in various countries. the International Conference on Changing Roles: New Roles, New Challenges. Noordwijk Aan Zee, The Netherlands.

Wong, A. K. D., Wong, F. K. W. \& Nadeem, A. 2011. Government roles in implementing building information modelling systems. Construction Innovation, 11, 61-76.

Wu, C., Xu, B., Mao, C.\& Li, X. 2017. Overview of BIM maturity measurement tools. Journal of Information Technology in Construction (ITcon), 22, 34-62. 
Wu, H. J. 2016. Research on Static Struture Analysis and Dynamic Evaluation of Building Industrialization Ecosystem. Master, Chongqing University.

Xia, L. Y. 2012. The Research on the Technique Spread Model and Selection of the Internet of Things of Our Country Master, Hunan University.

Yang, J.-B. \& Chou, H.-Y. 2018. Mixed approach to government BIM implementation policy: An empirical study of Taiwan. Journal of Building Engineering, 20, 337-343.

Zhou, Y., Yang, Y. \& Yang, J.-B. 2019. Barriers to BIM implementation strategies in China. Engineering, Construction and Architectural Management. 